\title{
Exercise Personal Training
}

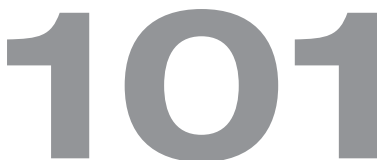


This page intentionally left blank 


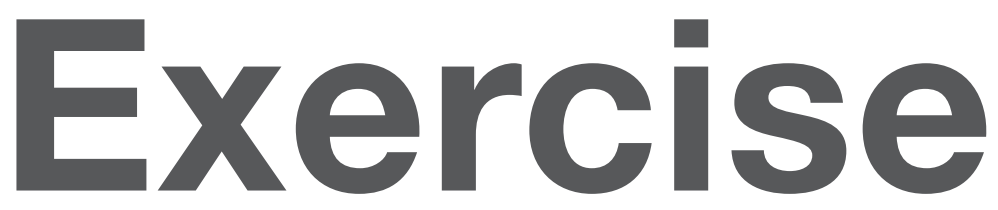

\section{Personal Training}

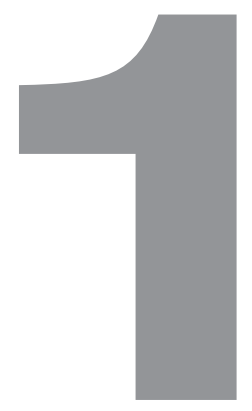

\section{Michael Chia Patricia Wong}

National Institute of Education, Singapore

\section{Noworld Scientific}




\title{
Published by
}

World Scientific Publishing Co. Pte. Ltd.

5 Toh Tuck Link, Singapore 596224

USA office: 27 Warren Street, Suite 401-402, Hackensack, NJ 07601

UK office: 57 Shelton Street, Covent Garden, London WC2H 9HE

\section{British Library Cataloguing-in-Publication Data}

A catalogue record for this book is available from the British Library.

\section{EXERCISE PERSONAL TRAINING 101}

Copyright (C) 2012 by World Scientific Publishing Co. Pte. Ltd.

All rights reserved. This book, or parts thereof, may not be reproduced in any form or by any means, electronic or mechanical, including photocopying, recording or any information storage and retrieval system now known or to be invented, without written permission from the Publisher.

\begin{abstract}
For photocopying of material in this volume, please pay a copying fee through the Copyright Clearance Center, Inc., 222 Rosewood Drive, Danvers, MA 01923, USA. In this case permission to photocopy is not required from the publisher.
\end{abstract}

Desk Editor: Tjan Kwang Wei

ISBN-13 978-981-4327-88-6

ISBN-10 981-4327-88-3

Printed in Singapore. 


\section{Experts' View}

The two authors have an outstanding track record of publications and applied work in the area of personal training and healthy lifestyle.

The key feature of this book is to help personal trainers to empower their clients with good problem-solving and decision-making skills concerning their health and well-being. This is a much needed addition to the literature. Several text books on personal training are available, however, the content of "Personal Training 101" is unique in that it provides applied and practical guidelines that cover a wide range of training and program issues. The book provides a holistic approach to personal training that is much needed to create lifestyle changes.

The book covers important training issues that are made accessible to the readers through topics such as concept statements, strategies for action, technology updates, in the news, key points and technical jargon, web-resources and follow-up references. The authors base their recommendations on research in exercise science, yet the communication of important personal training principles is accessible to everyone. The ability to translate research into practice is one of the most important assets of this book.

Jean Côté, Ph.D.

Professor and Director

School of Kinesiology and Health Studies

Queen's University, Canada 
Exercise Personal Training 101 offers a personal trainer a comprehensive guide to the professional practice of assisting individuals to achieve maximum health and fitness.

Authored by two individuals who are not only outstanding scholars in the field of exercise science, but have skillfully proven themselves to have the ability to translate hard scientific evidence into applied practices for all levels of exercise professionals. As one would expect from these authors, the book covers thoroughly and interestingly covers every aspect of Personal Training programmes, but in addition covers the professional topics of ethics, beliefs, client relations and programme design.

An added bonus to the book are the multiple appendices that offer clearly, compelling and complete examples that turn the ideas of the book into easily understandable and applicable professional practices. The well conceived content of contained in this book will easily move from the pages into the practice of every exercise personal trainer.

Paul G. Schempp, Ph.D.

Professor and Director

Sport Instruction Research Lab

University of Georgia

Athens, GA 30606

USA 


\section{About the Authors}

Dr Michael Chia is Head Physical Education \& Sports Science and Professor of Paediatric Exercise Physilogy at the National Institute of Education, Nanyang Technological University in Singapore. He was concurrently an Association of Commonwealth Universities and a Nanyang Technological University Staff Scholar for his doctoral studies in 1995-1998. He was Vice-President of the Education Research Association of Singapore and is the Vice-President of the Asian Council of Exercise and Sports Science, a BASES-accredited sports scientist (Physiology Research) and an ACSM Health and Fitness Director. He spent five years certifying Group Exercise Leaders and Health and Fitness Instructors for Singapore and the region for the ACSM and health professionals for the private sector. He is on the Editorial Boards of the International Journal of Sports Science and Coaching, Acta Kinesiologica, Sports Science, Asian Journal of Exercise and Sports Science and The Open Education Journal. He published more than 150 journal papers, book chapters, books, monographs and articles in print and on the internet and gave more than 50 keynote and invited presentations on sport, exercise, fitness and health issues in youth and adults to national and international audiences. His research expertise is in paediatric exercise physiology and health, physical education, personal training and health education. He is well-practised as a Consultant Exercise and Health Advisor and Trainer to the Senior Management Team of a multi-national corporation and served as trainer and chief examiner for the ACSM Health and Fitness Certification courses in Singapore. He is listed in the USA Marquis publication of Who's Who in Medicine and Healthcare and Engineering and Science. 
Dr Patricia Wong lectures in anatomy, exercise physiology and bioenergetics, health and wellness, nutrition, growth and development, and kinanthropometry since 1996. She graduated as an International Postgraduate Research Scholar from The University of Western Australia, where she won several academic honours and prizes during her undergraduate and postgraduate years. She is active in research in areas of obesity and exercise interventions, and has developed several specific research and educational softwares. She is also an internationally accreditated Anthropometrist and Instructor for the International Society for the Advancement of Kinanthropometry. She has served as a reviewer in the field of Exercise Physiology and Nutrition for the Asian Journal of Exercise and Sports Science and in Kinanthropometry for the Journal of Sports Sciences. She has developed teaching curriculum and modules serving in different capacities as a writer, editor, advisor and project director for different organisations in Singapore. Her expertise extends to educational, curriculum and professional development consultancy projects both locally and internationally, and has taught courses that address various pedagogical issues in teaching and learning. 


\section{Preface}

Personal Training 101 provides a message of empowerment for personal trainers who believe in the holistic development of their clients. The book is not just about the nuts and bolts of personal training or just about exercise or nutrition. Rather, it is about the holistic development of the client, being client-centred and process-centred as this will help ensure business longevity.

The key philosophy of the book is to help personal trainers to empower their clients with good problem-solving and decision-making skills concerning their health and well-being. This is done by subscribing and internalising HELP. HELP will serve new and experienced personal trainers in good stead in a more connected and globalised clientele. HELP explained is Health is available for Everyone who makes Lifetime changes and it is Personalised.

Using HELP, personal trainers can help all clients make personal lifetime and lifestyle changes that promote health, fitness and wellness. Good personal trainers become great personal trainers when they practise HELP with their clients and help them to become better problem-solvers and decision makers rather than telling them what to do, by offering sound and scientifically-based information that is personalised and appropriate. Additionally, the authors recommend that all personal trainers take PRIDE (personal responsibility in daily effort) in their stride, for garnering and polishing up their knowledge, skills and attitude (art and science) for great personal training.

Excellent personal trainers can be lifestyle and wellness coaches who are renowned for their great listening skills and high emotional quotient. They exceed client expectations at every opportunity. You can be one of them by making a start today. 
Part I (Chapters 1-4) of the book deals with generic personal training issues while Part II (Chapters 5-10) of the book deals with specific programmes issues. Special features in the book include concept statements, strategies for action, technology updates, in the news, key points, web-resources and follow-up references.

Personal Training 101 is a must-have, whether you are starting out in personal training or an experienced personal trainer.

Much appreciation and thanks are due to Scott Weng and Ellen Huang from Taipei, Taiwan, and Ho Wei Ching, Victoria Toh and Joanna Ho from Singapore, who were all excellent and gracious models in the photographs.

Dr Michael Chia and Dr Patricia Wong 


\section{Contents}

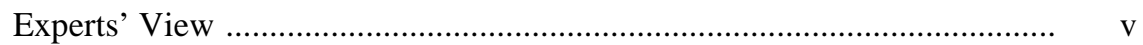

About the Authors ............................................................................ vii

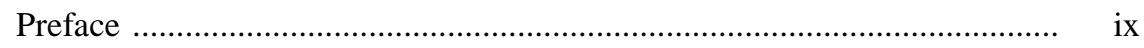

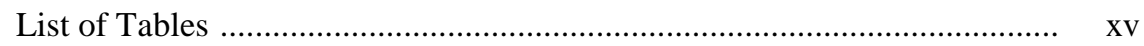

List of Figures ................................................................................. xvii

Part 1: Generic Personal Training Issues 1

Chapter 1

Fundamental Anchors and Beliefs in Personal Training ............................ 3

1.1 Introduction ...............................................................................

1.2 Essential Beliefs, Values and Qualities ............................................. 4

1.3 Personal Training Start-Up 101 ................................................... 8

1.4 Start Your Own Business ......................................................... 10

1.5 Action Strategies ..................................................................... 10

1.6 In the News .............................................................................. 11

1.7 Summary and Key Points ............................................................ 11

1.8 Recommended Readings and Website Resource ............................ 12

Chapter 2

Code and Ethics of Personal Training ......................................................... 13

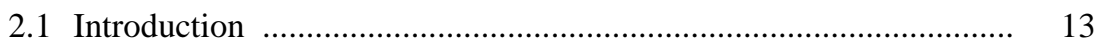

2.2 Code and Practice ..................................................................... 14

2.3 Action Strategies ........................................................................ 16

2.4 Summary and Key Points ......................................................... 17

2.5 Recommended Readings and Website Resource .............................. 17

Chapter 3

The First Client Meeting — Keeping It Real …….................................... 19

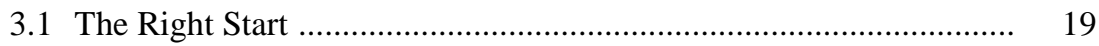

3.2 Determining Client Goals and Limitations ..................................... 22

3.3 Formalising Forms .............................................................. 22 
3.4 Action Strategies ....................................................................... 23

3.5 Summary and Key Points f...................................................... 23

Chapter 4

Effective Fitness Programme Design ...................................................... 25

4.1 Introduction ..................................................................... 25

4.2 Holistic Physical Fitness ..................................................... 26

4.3 Muscle Strength and Endurance Conditioning ................................ 27

4.4 Body Composition Monitoring ………….................................... 27

4.5 Cardiovascular Conditioning …………...................................... 28

4.6 Joint Flexibility Conditioning …………….................................... 29

4.7 General Principles of Training ………….................................. $\quad 30$

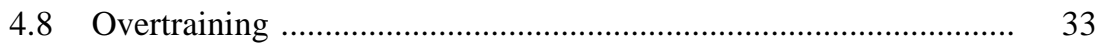

4.9 Incorporate Variety, Mixed or Cross-Training ................................ 34

4.10 Understanding Basic Sports Science …….................................. 34

4.11 Considerations When Training Outdoors ……............................... 40

4.12 Training in a Health Club ....................................................... 41

4.13 Training at Home ................................................................. 42

4.14 Action Strategies .............................................................. 42

4.15 In the News ........................................................................ 43

4.16 Summary and Key Points ............................................................ 43

4.17 Technology Updates .................................................................. 43

4.18 Recommended Readings and Website Resource ............................ 43

Part 2: Specific Programme Issues 45

Chapter 5

Designing the Flexibility Programme ..................................................... 47

5.1 Introduction .................................................................. 4

5.2 Health Benefits of Improved Flexibility .................................... 48

5.3 Anatomy of Stretching ……………..................................... 50

5.4 Basis Principles for Flexibility Training ……….......................... 52

5.5 Types of Flexibility Training ……………............................... 55

5.6 Other Flexibility-Based Activities and Training Aids .................... 60

5.7 Common Flexibility and Stretching Exercises .............................. 65

5.8 Action Strategies ................................................................ 72

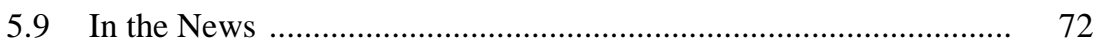

5.10 Summary and Key Points ......................................................... $\quad 72$

5.11 Recommended Readings and Website Resource ............................ 72 


\section{Chapter 6}

Designing Strength and Endurance Resistance Programmes ..................... 75

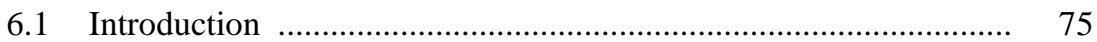

6.2 Different Methods of Resistance Training .................................... 76

6.3 Conducting the Workout: Essential Knowledge and Sequence ...... 78

6.4 Training for Muscular Endurance and Muscular Strength .............. 81

6.5 Sample Resistance Training Exercises ……….............................. 81

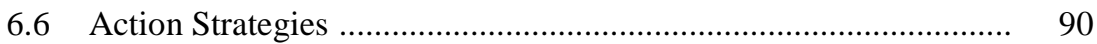

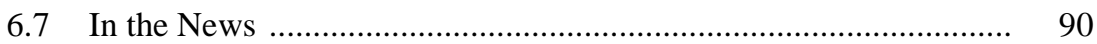

6.8 Summary and Key Points ........................................................ $\quad 90$

6.9 Suggested Readings and Website Resource ................................... 90

Chapter 7

Designing the Cardiovascular Programme ................................................. 91

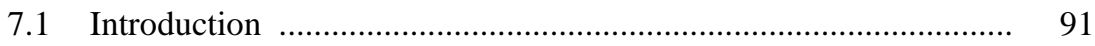

7.2 Basic Principles of the Energy Systems ......................................... 92

7.3 Principles of Training and Programming Adapting to Client's Needs .................................................................... 95

7.4 Estimated Energy Expenditure of Various Sports and Physical Activities .................................................................... 101

7.5 Three Basic Phases of a Training Session .................................... 104

7.6 Common Cardiovascular Activities ............................................. 105

7.7 Cardiovascular Machines and Equipment ..................................... 116

7.8 Monitoring Intensity of Cardiovascular Conditioning …................ 123

7.9 Action Strategies ................................................................. 129

7.10 In the News .................................................................... 129

7.11 Summary and Key Points ..................................................... 130

7.12 Recommended Readings and Website Resource ........................... 130 Chapter 8

Designing the Nutritional Programme ....................................................... 131

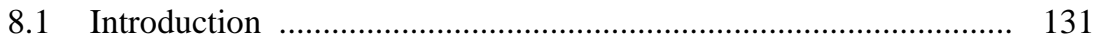

8.2 Professional Role of the Personal Trainer in Nutrition .................. 132

8.3 What is a Healthy Diet? ............................................................ 132

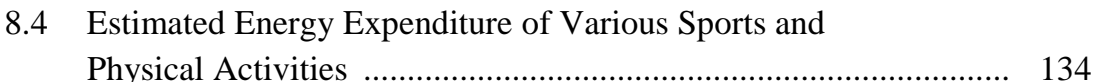

8.5 Understanding Hydration .......................................................... 140

8.6 Dietary Supplements and Ergogenic Aids .................................. 142

8.7 Principles of Effective Weight Management ................................ 147

8.8 Common Eating Disorders ......................................................... 149 


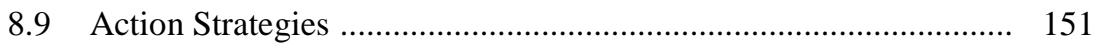

8.10 Summary and Key Points ...................................................... 151

8.11 Recommended Readings and Website Resource .......................... 152 Chapter 9

Individualising Programme Design ........................................................ 153

9.1 Clients Have Unique Needs .......................................................... 153

9.2 Theoretical Models that Explain Lifestyle Changes ...................... 155

9.3 The Meaning of Maintenance ..................................................... 157

9.4 Assessing Fitness .................................................................... 157

9.5 Common Testing Protocols ………......................................... 160

9.6 Monitoring Progress ................................................................. 179

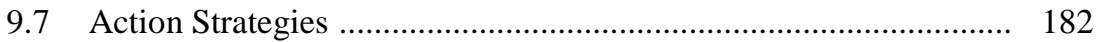

9.8 Summary and Key Points ........................................................... 183

9.9 Recommended Readings and Website Resource ........................... 183

Chapter 10

Exercise Considerations for Special Cases ……........................................ 185

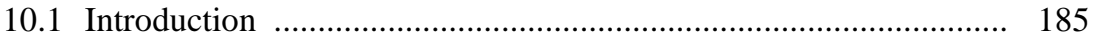

10.2 Exercise Planning for Managing Obesity …................................. 186

10.3 Exercise Planning for Older Adults ........................................... 188

10.4 Exercise Planning for the Asthmatics ............................................ 192

10.5 Action Strategies .................................................................. 194

10.6 Summary and Key Points ......................................................... 194

10.7 Recommended Readings and Website Resource ............................ 194 Appendix A

Client Acknowledgement and Indemnity ............................................... 197 Appendix B

Physical Activity Readiness Questionnaire ................................................. 199

Appendix C

Sample Exercise Accounts

Appendix D

Client's Training Diary ...................................................................... 203

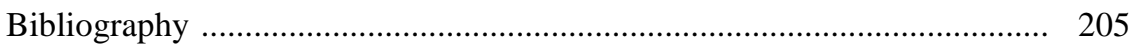




\section{List of Tables}

Table 4.1. The International Task Force For Obesity (IOTF) classification for Asians and World Health Organisation (WHO) classification for obesity for Europids are summarised

Table 4.2. A sample cross-training programme for a beginner ................ 34

Table 5.1. Useful steps or pointers for static stretching .......................... 56

Table 5.2. Useful steps or pointers for ballistic dynamic stretching ........ 56

Table 5.3. Useful guidelines or tips for PNF stretching ......................... 67

Table 6.1. Considerations for using isoinertial machines ....................... 76

Table 6.2. Considerations for using isokinetic machines ....................... 76

Table 6.3. Considerations for using body weight ................................ 76

Table 6.4. Considerations for using free weights .................................. 77

Table 6.5. Considerations for using resistance bands ............................ 77

Table 6.6. General information for muscular endurance and strength fitness training .............................................................. 81

Table 7.1. Characteristics of the ATP-CP system ................................... 93

Table 7.2. Characteristics of the Lactic Acid system .............................. 93

Table 7.3. Characteristics of the Oxygen Energy system ........................ 94

Table 7.4. General guidelines for designing cardiovascular exercise programme .............................................................. 96

Table 7.5. Energy expenditure in $\mathrm{kcal} / \mathrm{kg}$ body mass/hour ..................... 102

Table 7.6. Three main types of cardiovascular conditioning for aerobic fitness ......................................................................... 105

Table 7.7. Determining a range of training heart rates based on a percentage of the HRmax .................................................. 126

Table 7.8. Determining the training zone using the Karvonen formula ... 127

Table 7.9. An example adapted from the original Borg RPE scale ......... 128

Table 7.10. Common safety checks for signs/symptoms whilst client is exercising 
Table 8.1. Interpretations of serving size according to the Healthy Diet Pyramid recommendations ................................................ 134

Table 8.2. The three nutrients that contribute to estimated energy .......... 134

Table 8.3. A guide to the amounts of carbohydrate that can be consumed according to the various levels of exercise ............ 135

Table 8.4. Carbohydrate foods in 3 categories

Table 8.5. Estimated carbohydrate portions of some popular local Singapore foods

Table 8.6. Estimated recommended amounts of protein for various exercise levels

Table 8.7. General ways to monitor hydration status ............................. 141

Table 8.8. Two of the most common eating disorders ........................... 150

Table 9.1. Possible barriers and what the trainer can do ......................... 154

Table 9.2. An example of the ISAK Level 1 - Restricted Profile recording sheet

Table 9.3. An example of a trainer's observations made on a client's responses to training

Table 9.4. Examples of actions for self-monitoring and self-management 


\section{List of Figures}

Fig. 5.1. Sequence A (left picture) and Sequence B (right picture) of the anterior deltoid and pectorals PNF muscle stretch

Fig. 5.2. Sequence A (top picture) and Sequence B (bottom picture) of the hamstrings PNF muscle stretch

Fig. 5.3. Stability balls come in different sizes (top picture) and choosing the correct ball is important (bottom picture)

Fig. 5.4. Different types of neck stretching exercises 66

Fig. 5.5. Upper limb - triceps stretching exercise

Fig. 5.6. Upper limb - pectorals and deltoid posterior stretching exercises

Fig. 5.7. Upper limb - latissimus dorsi stretching exercise ...................... 67

Fig. 5.8. Lower limb - hamstrings stretching exercises ........................ 68

Fig. 5.9. Lower limb - quadriceps stretching exercise ............................ 68

Fig. 5.10. Lower limb - upper hamstrings, gluteals, adductors stretching exercises

Fig. 5.11. Lower limb - calf/gastrocnemius, achilles soleus stretching exercises

Fig. 5.12. Lower back - two versions of back flexion stretching exercises

Fig. 5.13. Lower back - two versions of back extension stretching exercises

Fig. 5.14. Lower back - piriformis and lower back rotation stretching exercise

Fig. 5.15. Lower back - two versions of back rotation stretching exercises

Fig. 6.1. Exercises using machines - seated lat pull down

Fig. 6.2. Exercises using machines - seated chest press

Fig. 6.3. Exercises using machines - seated deltoid raise

Fig. 6.4. Exercises using machines - seated shoulder pull 
Fig. 6.5. Exercises using machines - seated biceps curl ......................... 84

Fig. 6.6. Exercises using machines - standing tricep extension ............... 85

Fig. 6.7. Exercises using machines - seated leg press ............................ 85

Fig. 6.8. Exercises using machines - supine leg curl .............................. 86

Fig. 6.9. Exercises using machines - inclined curl up ............................. 86

Fig. 6.10. Exercises using machines - lower back extension ..................... 87

Fig. 6.11. Exercises using machines - hip flex ...................................... 87

Fig. 6.12. Exercises using free weights - supported tricep row ................ 88

Fig. 6.13. Exercises using body weight - push up ................................... 89

Fig. 6.14. Exercises using body weight - pull up ..................................... 89

Fig. 8.1. Recommended Healthy Diet Pyramid ..................................... 133

Fig. 9.1. A picture of a universal goniometer ........................................ 167

Fig. 9.2. Foot dorsi-plantar (left to right pictures) flexion - using a goniometer to measure ROM at the ankle joint ….................... 168

Fig. 9.3. Vertical jump test ............................................................... 171

Fig. 9.4. Backwards overhead shot put throw test .................................. 172 